\title{
Tunable bandpass filter based on photonic crystal fiber filled with multiple liquid crystals
}

Scolari, Lara; Tartarini, G.; Borelli, E.; Alkeskjold, Thomas Tanggaard; Mulvad, Hans Christian Hansen; Bassi, Paolo; Bjarklev, Anders Overgaard

\author{
Published in: \\ LEOS annual meeting
}

Link to article, DOI:

10.1109/LEOS.2007.4382406

Publication date:

2007

Document Version

Publisher's PDF, also known as Version of record

Link back to DTU Orbit

Citation (APA):

Scolari, L., Tartarini, G., Borelli, E., Alkeskjold, T. T., Mulvad, H. C. H., Bassi, P., \& Bjarklev, A. O. (2007). Tunable bandpass filter based on photonic crystal fiber filled with multiple liquid crystals. In LEOS annual meeting (pp. 319-320). IEEE. https://doi.org/10.1109/LEOS.2007.4382406

\section{General rights}

Copyright and moral rights for the publications made accessible in the public portal are retained by the authors and/or other copyright owners and it is a condition of accessing publications that users recognise and abide by the legal requirements associated with these rights.

- Users may download and print one copy of any publication from the public portal for the purpose of private study or research.

- You may not further distribute the material or use it for any profit-making activity or commercial gain

- You may freely distribute the URL identifying the publication in the public portal 


\title{
Tunable Bandpass Filter based on Photonic Crystal Fiber filled with Multiple Liquid Crystals
}

\author{
L. Scolari, G. Tartarini, E. Borelli, T. T. Alkeskjold, H. C. Hansen Mulvad, P. Bassi and A. Bjarklev
}

\begin{abstract}
A tunable bandpass filter based on a Photonic Crystal Fiber filled with two different Liquid Crystals is demonstrated. 130 $\mathrm{nm}$ bandwidth tunability is achieved by tuning the temperature from $30^{\circ} \mathrm{C}$ to $90^{\circ} \mathrm{C}$.
\end{abstract}

\section{INTRODUCTION}

Photonic crystal fibers (PCFs), microstructured waveguides with air holes running in the length direction of the fiber, present unique characteristics for realizing all-in-fiber devices. An appropriate design of a PCF allows light to be guided by so called modified Total Internal Reflection (m-TIR) [1]. However, if the holes of such a fiber are filled with a material having a refractive index higher that of silica, anti-resonances of the highindex cylinders give rise to discrete photonic bandgaps where light is confined to the core [2]. This effect has been obtained by filling the holes of a PCF with high-index fluids [3] and with liquid crystals (LCs) [4]. The manipulation of the bandgap position in LC filled PCF (LCPCF) can be achieved by thermally, electrically or optically controlling the optical properties of the infiltrated LC. Furthermore, the shape of the bandgaps can be tailored, for example, by tapering the fiber before the infiltration [5].

Broadband bandpass filters can be used in applications such as, for example, Optical Coherence Tomography (OCT) or Optical Low-Coherence Reflectometry. The tunability of the bandwidth represents a degree of freedom well desired in these applications. An all-in-fiber tunable bandpass filter has been demonstrated by applying a thermal gradient to a PCF filled with a high index fluid [6]. Here we demonstrate a tunable bandpass filter obtained by filling two different LCs in a PCF. The tunability is achieved

L. Scolari, T. T. Alkeskjold, H. C. Hansen Mulvad and A. Bjarklev are with COM.DTU Department of Communications, Optics and Materials, Technical University of Denmark, Ørsteds Plads, Building 345V, DK-2800 Kgs. Lyngby, Denmark (e-mail: 1sc@,com.dtu.dk)

G. Tartarini, E. Borelli and P. Bassi are with DEIS Dipartimento di Elettronica, Informatica e Sistemistica, Viale Risorgimento, 2, University of Bologna, I-40136, Italy by uniformly controlling the temperature of one LC, without the need of a thermal gradient. Moreover, the shape of the fabricated filter is Gaussian-like, allowing the filter to be used in OCT, where a Gaussian spectrum is required. For example, the tunability of the bandwidth would allow optimization of the OCT system. The experimental results presented here are also reproduced by simulations.

\section{DEVICE PRINCIPLE AND EXPERIMENTAL RESULTS}

The fiber used in the experiment is LMA-10, from Crystal Fibre A/S, with a solid core surrounded by 4 rings of air holes arranged in a triangular lattice. The hole diameter is $2.9 \mu \mathrm{m}$ and the inter-hole distance is $6.6 \mu \mathrm{m}$. Two different LCs are infiltrated for $9 \mathrm{~mm}$ each in two sections of fiber. The two endfacets are then butt-coupled, as shown Fig. 1(a). All the holes are infiltrated. Light from a supercontinuum source is coupled to the device and the transmission spectrum measured with an optical spectrum analyzer (OSA).

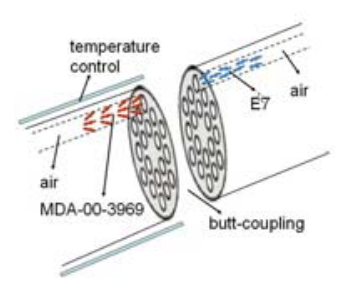

(a)

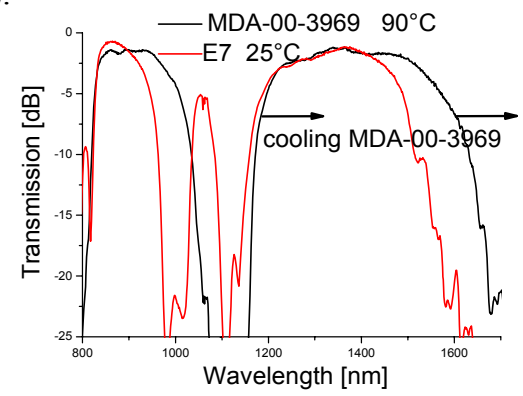

(b)
Fig.1 (a) Schematic illustration of the device. (b) Transmission spectrum of LMA-10 filled with $\mathrm{E} 7,25^{\circ} \mathrm{C}$ (red) and transmission spectrum of LMA-10 filled with MDA-00-3969, $90^{\circ} \mathrm{C}$ (black). The bandgaps caused by MDA-00-3969 shift towards longer wavelengths across the E7 bandgaps when the temperature of MDA-00-3969 is decreased. The resulting overlap of the two spectra is therefore narrowed by decreasing the temperature.

When two LCs are present in a PCF, the resulting transmission spectrum is the overlap of the two different spectra. When the 
temperature of one LC is increased, the bandgaps related to that LC shift and the overlap is narrowed or enlarged depending on the direction of the bandgap shift. The two LCs used here are both form Merck: E7, a nematic LC with planar alignment (ordinary and extraordinary index $\mathrm{n}_{\mathrm{o}}=1.52$ and $\mathrm{n}_{\mathrm{e}}=1.75$, respectively) and MDA-00-3969, nematic, with $45^{\circ}$ splayed alignment $\left(\mathrm{n}_{\mathrm{o}}=1.4978\right.$ and $\left.\mathrm{n}_{\mathrm{e}}=1.7192\right)$. The transmission spectra of each individual LCPCF section are illustrated in Fig. 1. Here MDA-00-3969 is heated to $90^{\circ} \mathrm{C}$, while $\mathrm{E} 7$ is at room temperature $\left(25^{\circ} \mathrm{C}\right)$ and the overlap of the two spectra covers the region 1170-1600 $\mathrm{nm}$. If MDA-00-3969 is cooled, the bandgaps caused by this LC move towards longer wavelengths and, consequently, the overlap is narrowed, reduced to $1300-1600 \mathrm{~nm}$ at $30^{\circ} \mathrm{C}$. This allows the fabrication of filters with a continuously tunable bandwidth. The transmission spectrum in the linear scale for different temperatures is shown in Fig. 2, together with a Gaussian fit to the $30^{\circ} \mathrm{C}$ measurement. The loss is $4 \mathrm{~dB}$ at the central wavelength of the filter.

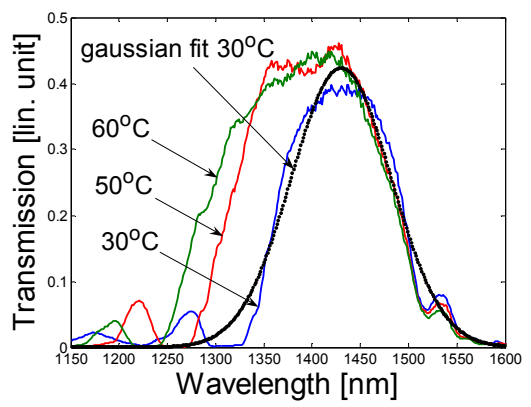

Fig.2 Transmission spectrum of the fabricated device in linear units as a function of increasing temperature of MDA-00-3969.

\section{SIMULATIONS}

We modelled our experimental results with a finite element solver, able to study anisotropic waveguides both in guided [7] and leaky [8] regimes. The simulation program utilizes a particular kind of radiation boundary conditions which have proved to give optimal results in the determination of the complex propagation constant $\beta_{\mathrm{c}}=\beta$-j $\alpha$ of leaky modes, where $\beta$ is the phase constant of the mode analyzed and $\alpha$ is the term which accounts for the radiation losses of the mode. A particularly interesting feature of this modeling tool is that it can solve structures exhibiting arbitrary dielectric tensors $\varepsilon$, and is therefore particularly appropriate in the study of these LCPCF which exhibit splay-alignment of the mesogens and which therefore may in principle feature all the nine component of $\varepsilon$ to be nonzero. Coupling losses generated from different interfaces in the device (air-E7, E7-MDA-00-3969, MDA-00-3969-air) are calculated and added to the simulated confinement losses. The total calculated loss is shown in Fig. 3. We observe a shift of about $40 \mathrm{~nm}$ of the central wavelength between Fig. 2 and Fig. 3 and also a higher increase in the transmission as a function of temperature for Fig. 3 with respect to Fig. 2. We believe that this is due to the fact that the simulations are made for a perfect uniform structure, without taking into account small uniformities present in a real PCF and variation of the hole size along its length. Moreover, the refractive indices of the LCs are measured in the visible range and extrapolated to infrared wavelengths.

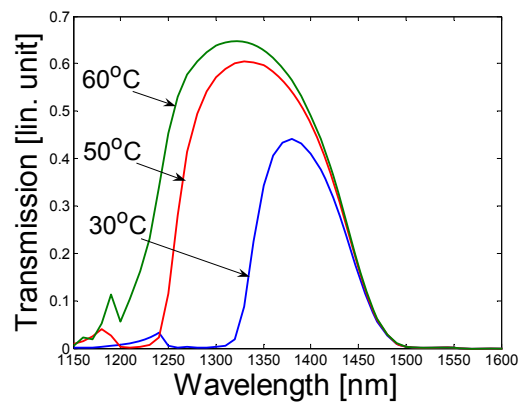

Fig.3 Simulated transmission spectrum (coupling loss and confinement loss) as a function of increasing temperature of MDA-00-3969.

\section{CONCLUSION}

We have demonstrated a continuously tunable passband filter by filling two different LCs in a PCF. This filter, compared to single LC filling, offers more flexible bandwidth tunability. In particular, $130 \mathrm{~nm}$ bandwidth tunability is achieved in the temperature range $30^{\circ} \mathrm{C}-90^{\circ} \mathrm{C}$. The tuning characteristics of this device have also been successfully modelled by using a finite element code, which takes into account the anisotropy of the LCs. Considering the large number of available temperaturetunable LCs, we therefore believe that LCPCF devices based on multiple LCs can be a promising candidate for all-in-fiber broadband filters for a variety of applications, e.g. OCT or OLCR, where bandwidth tunability would allow for optimization of the resulting transmission spectrum.

\section{REFERENCES}

[1] P. Russell, "Photonic crystal fibers," Science vol. 299, 358-362, 2003.

[2] N. M. Litchinitser et al., "Antiresonant reflecting photonic crystal optical waveguides," Opt. Lett., vol. 27, no 18, pp. 1592-1594, 2002.

[3] R.T. Bise et al., "Tunable photonic band gap fiber," Optical Fiber Communication Conference Technical Digest Washington, DC, pp. 466$468,2002$.

[4] T.T. Larsen et al., "Optical devices based on liquid crystal photonic bandgap fibers," Opt. Express, vol. 11, no 20, pp. 2589-2596, 2003.

[5] L. Scolari et al., "Tunable gaussian filter based on tapered liquid crystal photonic bandgap fibre," Elect. Lett., vol. 42, no. 22, pp. 1270-1271, 2006.

[6] P. Steinvurzel et al., "Continuously tunable bandpass filtering using highindex inclusions microstructured optical fibre," Elect. Lett., vol. 41, no. 8, pp. 463-464, 2005.

[7] I. Cristiani et al., "Nonlinear characterization and modeling of periodically poled lithium niobate waveguides for $1.5-\mu \mathrm{m}$-band cascaded wavelength conversion," Opt. Comm., vol. 187, pp. 263-270, 2001.

[8] G. Tartarini et al., "Experimental and theoretical analysis of leaky extraordinary modes in negative uniaxial channel waveguides," Opt. Comm., vol. 253, pp. 109-117, 2005. 